\title{
Rainfastness of poly(vinyl alcohol) deposits on Vicia faba leaf surfaces: from laboratory-scale washing to simulated rain
}

Article

Published Version

Creative Commons: Attribution 3.0 (CC-BY)

Open access

Symonds, B. L., Thomson, N. R., Lindsay, C. I. and Khutoryanskiy, V. V. (2016) Rainfastness of poly(vinyl alcohol) deposits on Vicia faba leaf surfaces: from laboratory-scale washing to simulated rain. ACS Applied Materials and Interfaces, 8 (22). pp. 14220-14230. ISSN 1944-8244 doi: https://doi.org/10.1021/acsami.6b01682 Available at https://centaur.reading.ac.uk/64961/

It is advisable to refer to the publisher's version if you intend to cite from the work. See Guidance on citing.

Published version at: http://pubs.acs.org/doi/abs/10.1021/acsami.6b01682

To link to this article DOI: http://dx.doi.org/10.1021/acsami.6b01682

Publisher: American Chemical Society

All outputs in CentAUR are protected by Intellectual Property Rights law, including copyright law. Copyright and IPR is retained by the creators or other copyright holders. Terms and conditions for use of this material are defined in the End User Agreement. 


\section{CentAUR}

Central Archive at the University of Reading

Reading's research outputs online 


\title{
Rainfastness of Poly(vinyl alcohol) Deposits on Vicia faba Leaf Surfaces: From Laboratory-Scale Washing to Simulated Rain
}

\author{
Brett L. Symonds, ${ }^{\dagger}$ Niall R. Thomson, ${ }^{\ddagger}$ Christopher I. Lindsay, ${ }^{\ddagger}$ and Vitaliy V. Khutoryanskiy ${ }^{*} \dagger$ \\ ${ }^{\dagger}$ Reading School of Pharmacy, The University of Reading, Whiteknights, P.O. Box 224, Reading RG6 6AD, U.K. \\ ‡Syngenta, Jealott’s Hill International Research Centre, Bracknell, Berkshire RG42 6EY, U.K.
}

\section{Supporting Information}

ABSTRACT: Rainfastness is the ability of agrochemical deposits to resist wash-off by rain and other related environmental phenomena. This work reports laboratory-scale and raintower studies of the rainfastness of fluorescently labeled poly(vinyl alcohol) (PVA) using fluorescent microscopy combined with image analysis. Samples of hydrolyzed PVA exhibit improved rainfastness over a threshold molecular weight, which correlates with PVA film dissolution, swelling, and crystalline properties. It was also established that the rainfastness of PVA scaled with the molecular weight over this threshold. These PVA samples were further characterized in order to determine the effect of the crystallinity on rainfastness. The quantification of rainfastness is of great interest to the field of agrochemical formulation development in order to improve the efficacy of pesticides and their adjuvants.

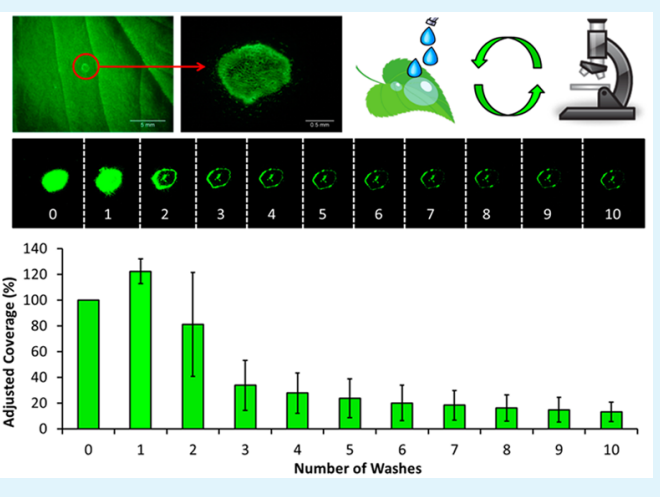

KEYWORDS: poly(vinyl alcohol), fluorescent labeling, microscopy, rainfastness, 5-DTAF, Vicia faba, field bean, agrochemical, adjuvant

\section{INTRODUCTION}

The world faces the important challenge of securing a sustainable food supply for a growing population. The Food and Agricultural Organization of the United Nations expects that global agricultural production will have to increase by $60 \%$ from 2005-2007 levels in order to feed an estimated 9 billion people in 2050. ${ }^{1}$ Agrochemicals are utilized to improve crop production and yield; they take the form of pesticides, fertilizers, growth agents, and adjuvants. ${ }^{2-7}$ These treatments may take the form of seed or soil treatments or sprayed mixtures and are almost always a formulation of more than one component. $^{8,9}$ Such formulations can be subject to losses from a number of sources no matter the method of application and are prepared and applied so as to reduce these losses as much as possible. ${ }^{6,7,10}$ As an example of formulation, if an active ingredient is not readily water-soluble, then adjuvants can be added to form emulsions, to increase solubility, or to otherwise create a stable solution. ${ }^{2,11}$

An outline of the agrochemical delivery process and potential losses is as follows: Losses may begin during the initial spraying process; if weather conditions are not ideal, then spray drift can occur. ${ }^{5}$ This spray drift results in a waste of formulation and unnecessary pollution of the surrounding environment, not to mention the detrimental effects of unprotected crops. ${ }^{6}$ Even when sprayed droplets hit their intended target, they may have poor retention on plant surfaces. This is related to the physicochemical properties of the spray droplet during its formation from a spray nozzle and its initial impact with plant surfaces. ${ }^{12-15}$ Once the droplet has been retained, further losses can occur because of poor retention of this droplet or its dry deposit. This is often caused by microbial, photolytic, or hydrolytic degradation or removal by adverse environmental conditions such as rain or even strong agitation such as by wind. ${ }^{3,5,16}$ Considering the multitude of factors above, agrochemical formulations are subject to much research and development aimed at reducing and overcoming these losses. ${ }^{17-30}$ This contribution will focus on research to reduce the impact of one such loss mechanism: losses due to rain and related phenomena. Specifically, we examine the retention of dry deposits of poly(vinyl alcohol) (PVA), a commercially available water-soluble polymer.

Rainfastness describes the ability of a compound to resist removal or wash-off due to rain and other environmental effects. Rainfastness advice is often provided on agrochemical product labels with information about how long a product needs to be allowed to dry before it is rainfast. If a product does not have this advice or if rainfastness is poor, then farmers are potentially subject to weather conditions. Therefore, quantification of rainfastness is valuable for the intelligent design of agrochemical formulations.

Polymeric adjuvants are already used commercially in agriculture. 6 Products containing polymeric formulations include the "Nu Film" range (Miller) and "Newman Cropspray 11-E" and "Bond" (both De Sangosse). In general, they are

Received: February 8, 2016

Accepted: April 12, 2016 
Table 1. Characteristics of Fluorescently Labeled and Unlabeled PVA Samples

\begin{tabular}{|c|c|c|c|c|c|c|c|c|c|c|}
\hline \multirow[b]{2}{*}{ name } & \multirow[b]{2}{*}{ supplier } & \multicolumn{2}{|c|}{$\underset{(\%)}{\operatorname{DoH}\left({ }^{1} \mathrm{H} \text { NMR }\right)}$} & \multirow[b]{2}{*}{$\begin{array}{l}M_{\mathrm{w}}(\mathrm{GPC}) \\
\quad(\mathrm{kDa})\end{array}$} & \multirow[b]{2}{*}{$\begin{array}{l}M_{\mathrm{n}}(\mathrm{GPC}) \\
\quad(\mathrm{kDa})\end{array}$} & \multirow[b]{2}{*}{$\begin{array}{c}\text { PDI }\left(M_{\mathrm{w}} /\right. \\
\left.M_{\mathrm{n}}\right)\end{array}$} & \multirow[b]{2}{*}{$\begin{array}{l}\text { equivalent }[5-\mathrm{DTAF}] \\
(\mathrm{mg} / \mathrm{mL})^{a}\end{array}$} & \multirow[b]{2}{*}{$\begin{array}{l}\text { alcohol moieties } \\
\text { labeled }(\%)^{a}\end{array}$} & \multicolumn{2}{|c|}{$\begin{array}{l}\text { crystallinity } \\
(\%)\end{array}$} \\
\hline & & labeled & unlabeled & & & & & & DSC & WAXS \\
\hline PVA-80 & $\begin{array}{l}\text { Sigma- } \\
\text { Aldrich }\end{array}$ & 84.7 & 79.1 & $9.0^{b}$ & N/A & $\mathrm{N} / \mathrm{A}$ & 0.009 & 0.023 & 10.7 & 17.7 \\
\hline PVA-88L & Alfa Aesar & 91.9 & 85.3 & 20.3 & 17.4 & 1.17 & 0.008 & 0.018 & 39.2 & 43.6 \\
\hline PVA-88M & Alfa Aesar & 90.6 & 86.7 & 27.7 & 12.6 & 2.19 & 0.007 & 0.016 & 10.4 & 19.2 \\
\hline PVA- $88 \mathrm{H}$ & Alfa Aesar & 90.8 & 86.2 & 33.1 & 15.0 & 2.20 & 0.006 & 0.013 & 10.0 & 18.1 \\
\hline PVA-99L & Alfa Aesar & 98.9 & 98.8 & 21.7 & 13.5 & 1.61 & 0.010 & 0.021 & 34.3 & 15.3 \\
\hline PVA-99M & Alfa Aesar & 98.8 & 98.6 & 51.3 & 32.4 & 1.58 & 0.007 & 0.015 & 30.0 & 28.0 \\
\hline PVA-99H & Alfa Aesar & 98.9 & 98.7 & 66.3 & 43.1 & 1.54 & 0.008 & 0.016 & 27.5 & 53.2 \\
\hline $\begin{array}{l}\text { PVA- } \\
\text { 99VH }\end{array}$ & $\begin{array}{l}\text { Sigma- } \\
\text { Aldrich }\end{array}$ & 99.4 & 98.7 & 93.2 & 65.1 & 1.43 & 0.009 & 0.020 & 27.0 & 43.6 \\
\hline
\end{tabular}

termed "wetters", "spreaders", "stickers", "retention aids”, and "deposition aids". Modes of action are diverse: wetters and spreaders increase foliar coverage; stickers and retention aids are designed to reduce losses to environmental effects; deposition aids improve the ability of the formulations to arrive from spray nozzle to leaf surface. The chemistry of $\mathrm{Nu}$ Film is based on polymeric terpenes-naturally occurring organic molecules and polymers and their derivatives-which are film forming. Polymers that form films after application are common, and this seems to be the mode of action for much of the adjuvancy exhibited by polymeric formulations. ${ }^{31,32}$

Many studies have examined the retention of liquid formulations as they impact a leaf surface or as a liquid droplet on the surface. ${ }^{33-36}$ Prior work has also provided several methods for determining the impact of simulated rain on pesticide deposits, such as copper-based fungicides. ${ }^{37}$ However, despite the aforementioned commercially available polymercontaining agrochemical products, there is a lack of published literature regarding rainfastness of polymers as dry deposits; in particular, extensive studies that examine different grades of the same polymer seem to be lacking. Correlating the fundamental properties and characteristics of PVA deposits, films, and solutions to its performance as a rainfastness aid will facilitate this understanding and ultimately improve the intelligent design of agrochemical formulations. In order to achieve this, the current work has established a method to quantify rainfastness based on fluorescent microscopy. PVA was labeled and washed off of leaf surfaces using two different washing methods, with the coverage monitored by using a fluorescent microscope and processing the resulting images. We present a small laboratory-scale washing method that can be used to quickly measure the rainfastness of any fluorescent species and in addition a method incorporating artificially generated rain.

\section{EXPERIMENTAL SECTION}

2.1. Materials. Two samples of poly(vinyl alcohol) (PVA) were purchased from Sigma-Aldrich (PVA80 and PVA99VH), and six samples were purchased from Alfa Aesar (PVA88L, PVA88M, PVA88H, PVA99L, PVA99M, and PVA99H). 5-(4,6Dichlorotriazinyl)aminofluorescein (5-DTAF), sodium nitrate, and sodium carbonate were purchased from Sigma-Aldrich.

2.2. Characterization of PVA. Samples of PVA with varying molecular weights and degrees of hydrolysis $(\mathrm{DoH})$ were used in this study (Table 1). Solutions of these samples were characterized via ${ }^{1} \mathrm{H}$ NMR and gel permeation chromatography (GPC). In order to dissolve PVA, it is necessary to heat the solution to approximately 90 ${ }^{\circ} \mathrm{C}$ for $1-2 \mathrm{~h}$ with constant stirring. Failure to stir will result in a conglomeration of the PVA granules into a gel. After dissolution, PVA solutions were allowed to cool at ambient conditions for several hours, with constant stirring. As a result, the solutions of PVA were completely clear, with no undissolved polymer detectable by eye. Solution-cast films of the polymers were prepared, and their solubility and swelling were characterized in water via a gravimetric method. The crystallinity of PVA in films was also characterized by both dynamic scanning calorimetry (DSC) and wide-angle X-ray scattering (WAXS). Further, characterization via the measurement of static contact angles on certain surfaces was performed with an Attension Theta Lite goniometer. The specific systems measured were droplets of PVA solutions on Vicia faba leaf surfaces and droplets of deionized water on PVA film surfaces.

2.2.1. ${ }^{1} \mathrm{H} N M R$. Spectra for PVA were recorded (Brüker $400 \mathrm{MHz}$ spectrometer, in $\mathrm{D}_{2} \mathrm{O}$ ) in order to characterize the $\mathrm{DoH}$, i.e., the content of vinyl acetate groups. The spectra were analyzed and peaks integrated using MestReNova Lite software (Mestrelab Research). Peaks in the region $1.50-1.80 \mathrm{ppm}$ are caused by protons of backbone $-\mathrm{CH}_{2}$, while those at $2.10 \mathrm{ppm}$ are caused by protons of pendant acetate $-\mathrm{CH}_{3}$ moieties. Peaks at $3.85 \mathrm{ppm}$ are backbone $-\mathrm{CH}$ opposite acetate moieties and $4.05 \mathrm{ppm}$ are backbone $-\mathrm{CH}$ opposite to the hydroxyl moieties (Figure S1). By integration of these peaks, it is possible to determine the DoH for PVA samples (eq 1):

$$
\mathrm{DoH}=\left(1-\frac{b}{d}\right) \times 100 \%
$$

where $b$ and $d$ are the integral values for ${ }^{1} \mathrm{H}$ NMR peaks at 4.05 and $3.85 \mathrm{ppm}$, respectively.

2.2.2. GPC. PVA samples were dissolved in a $0.05 \mathrm{M}$ sodium nitrate solution to a concentration of $0.1 \% \mathrm{w} / \mathrm{w}$ by heating to $90{ }^{\circ} \mathrm{C}$. The 0.05 $\mathrm{M}$ sodium nitrate solution was used as the eluent as the samples were run through an aqueous column (Agilent PL Aquagel-OH Mixed-H 8 $\mu \mathrm{m})$ at a rate of $0.1 \mathrm{~mL} / \mathrm{min}$ and run at room temperature. A set of standards of known molecular weight poly(ethylene glycol) were run in the same manner. The Agilent GPC with a refractive index detector was used to determine the hydrodynamic volume of the samples, and software determined unknown PVA molecular weights using MarkHouwink parameters from the literature (eq 2):

$$
V_{\mathrm{h}}=\frac{2}{5} \frac{K M^{1+\alpha}}{N_{\mathrm{A}}}
$$

where $V_{\mathrm{h}}$ is the hydrodynamic volume, $M$ is the molecular weight, and $K$ and $\alpha$ are the Mark-Houwink parameters. It can be used to convert the hydrodynamic volume determined via GPC to molecular weight.

2.2.3. Swelling and Solubility. A gravimetric measurement was used to determine the swelling and solubility of solution-cast PVA films. Solutions were cast in plastic Petri dishes and dried at room temperature for at least $72 \mathrm{~h}$ to form films of approximately $1 \mathrm{~g}$ of mass, with the water content in the range of $3.8-7.6 \%$ by weight (Table S1). The thicknesses of the films were measured with digital 


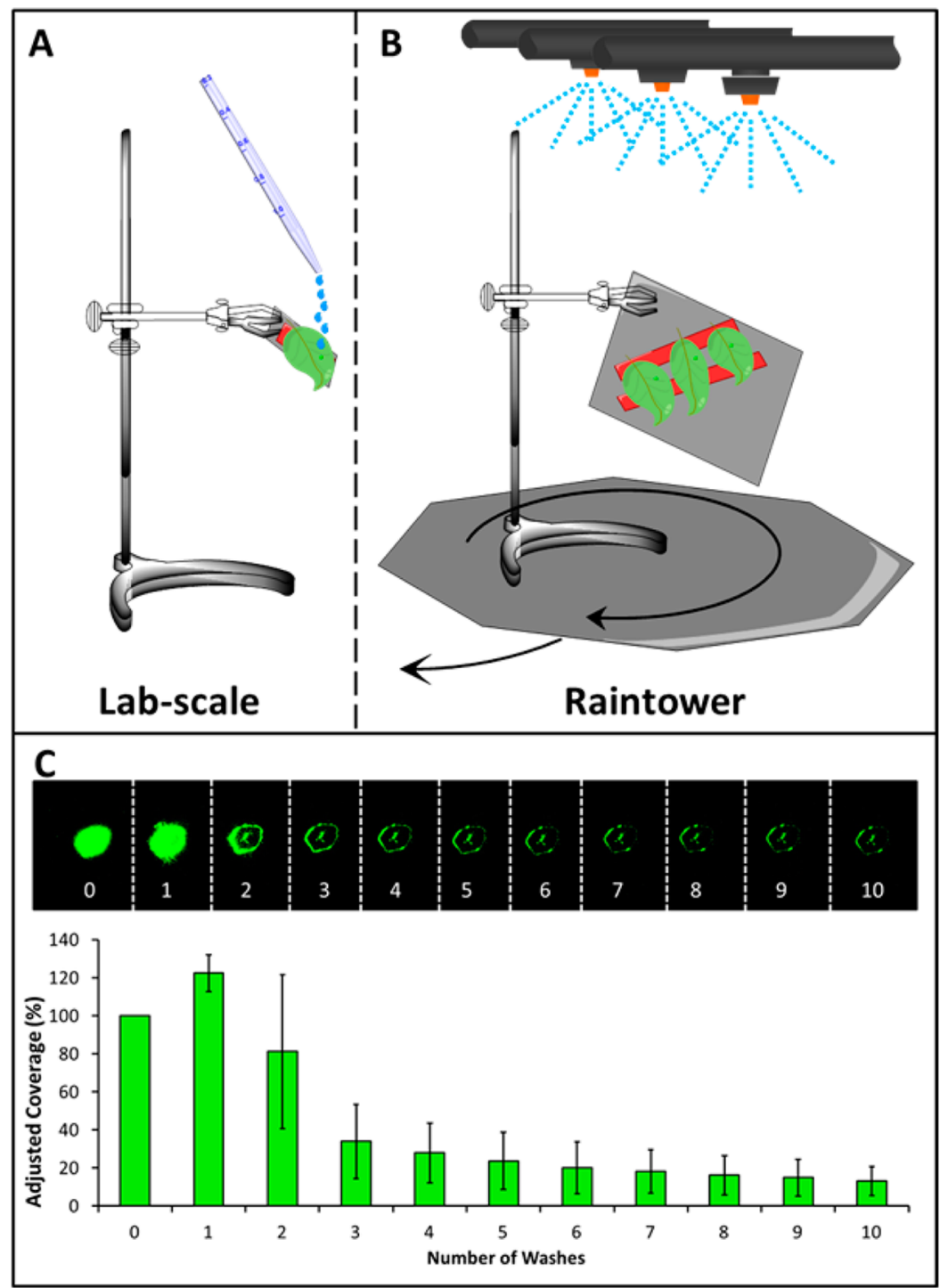

Figure 1. (A and B) Laboratory-scale and raintower washing methods, respectively (C) Exemplary wash-off profile of a labeled deposit of PVA with corresponding (processed via ImageJ) pictures, where the area of coverage in the pictures is quantified with ImageJ and plotted.

calipers and found to be between 80 and $160 \mu \mathrm{m}$ depending on which area of the film was measured. The films were initially weighed and then placed in $500 \mathrm{~mL}$ of deionized water without any stirring or agitation, and their masses were weighed periodically. The three temperatures used were 5,15 , and $25{ }^{\circ} \mathrm{C}$, which were controlled with a water bath, so as to mimic a moderate climatic range. The swelling degree (SD) was determined at each temperature and in triplicate using eq 3 :

$$
\mathrm{SD}=\frac{m-m_{0}}{m_{0}}
$$

where $m$ is the mass of the film at time $t$ and $m_{0}$ is the mass of the initial dry film.

2.2.4. Crystallinity. WAXS and DSC were used to determine the crystallinity of PVA in solution-cast PVA films, which were prepared as described in section 2.2.3. For WAXS, using a Brüker Nanostar, data were collected for $1 \mathrm{~h}$ and retrieved using a Fujifilm FLA-7000 reader and diffraction patterns were analyzed using ImageJ software (National Institutes of Health). The crystallinity was based on the ratio of crystalline peak areas to amorphous areas. An exemplary WAXS diffraction pattern is shown in Figure S2. DSC was performed using a TA Q2000 instrument, and the temperature was ramped from 30 to $250{ }^{\circ} \mathrm{C}$, cooled to $30{ }^{\circ} \mathrm{C}$, and again ramped up to $250{ }^{\circ} \mathrm{C}$ at a rate of $10{ }^{\circ} \mathrm{C} / \mathrm{min}$. An exemplary DSC thermogram is shown in Figure S3.
The enthalpy of fusion of the second heating was used to determine the crystallinity (eq 4). The solid content of the films was determined via thermogravimetric analysis using a TA Q50 instrument and heating samples from 20 to $200{ }^{\circ} \mathrm{C}$ at a rate of $10{ }^{\circ} \mathrm{C} / \mathrm{min}$.

$$
\chi_{\mathrm{c}}=\frac{\Delta H_{\mathrm{m}}}{\Delta{H_{\mathrm{m}}}^{\circ} \omega}
$$

where $\chi_{\mathrm{c}}$ is the crystallinity, $\Delta H_{\mathrm{m}}$ is the enthalpy of melting of the second heating, $\Delta H_{\mathrm{m}}{ }^{\circ}$ is the enthalpy of melting for $100 \%$ crystalline PVA from the literature, and $\omega$ the weight fraction of the solid film content. ${ }^{38}$

2.2.5. Polarized Light Microscopy (PLM). In addition to the WAXS and DSC measurements undertaken to determine the crystallinity quantitatively, certain PVA films were examined using PLM. A Leica DM2500 M microscope fitted with polarized filters and a digital camera was used to acquire images of films that were solution-cast at ambient room temperature conditions onto two different surfaces. A volume of $1 \mathrm{~mL}$ of $4 \%$ PVA solution was pipetted onto both a glass slide and a parafilm surface. Films cast on parafilm were detached and imaged on glass slides because the technique requires light to be transmitted through the sample. Light passes through an initial polarizing filter before the sample and through a second polarizer, known as the analyzer, after the sample. The analyzer is aligned to only 

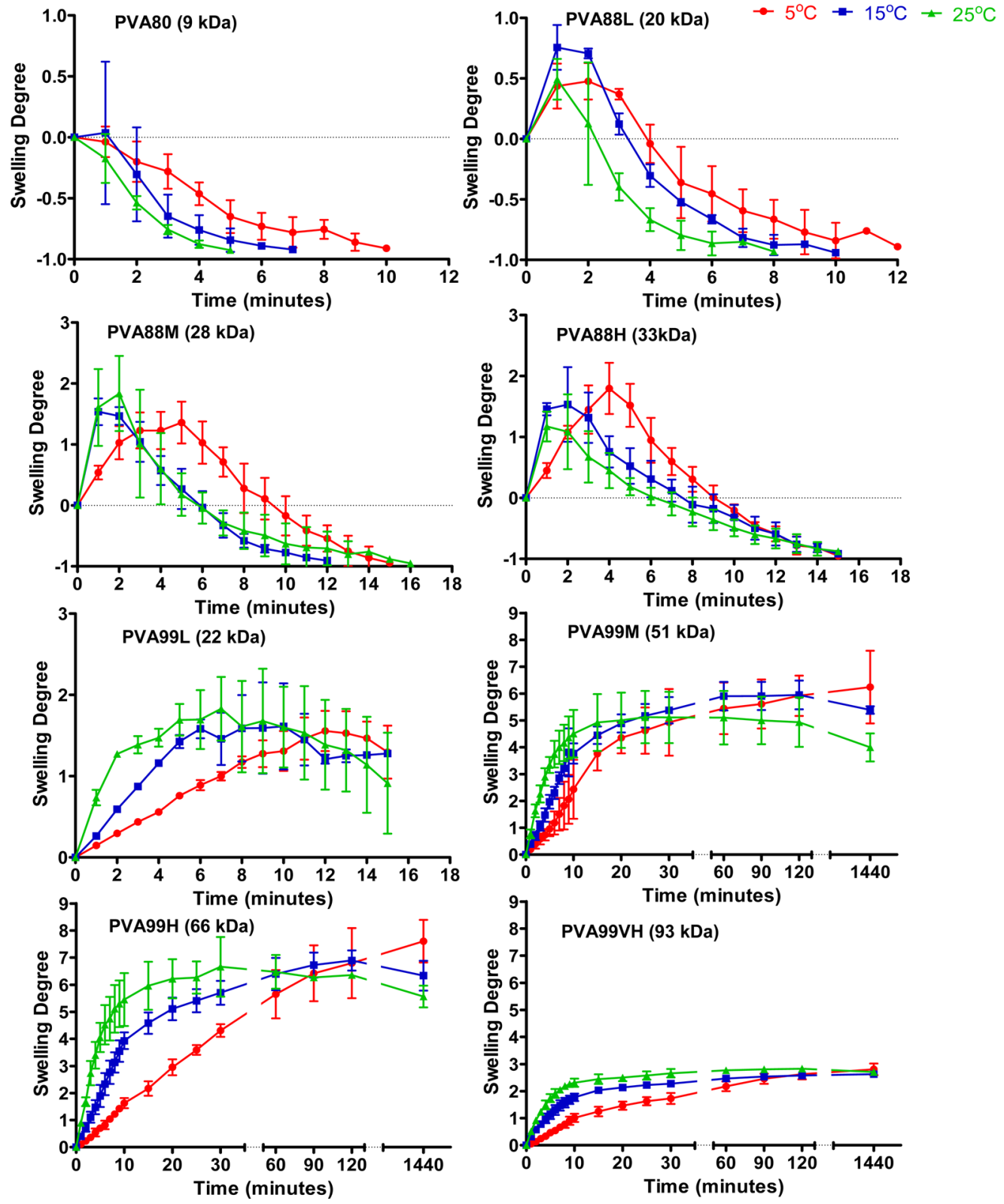

Figure 2. Swelling and dissolution of PVA films in water at 5, 15, and $25^{\circ} \mathrm{C}$. Each experiment was performed in triplicate, and the data are presented as mean value \pm standard deviation.

allow light perpendicular to the vibrational direction of the light that the polarizer allows; that is, no light may pass through both filters when no sample is present. Thus, the field of view is completely dark when an isotropic sample such as glass is placed into the light path, and contrast is only achieved with an anisotropic specimen.

2.3. Fluorescent Labeling of PVA. PVA was chemically labeled with a derivative of fluorescein reactive to hydroxyl groups, 5-DTAF. To a $10 \mathrm{~mL}$ solution $(0.4 \% \mathrm{w} / \mathrm{w})$ of PVA was added a mass of fluorophore equivalent to react with $1 \%$ of PVA alcohol groups with the assumption that each fluorophore may only react with one hydroxyl moiety. The masses added were $3.9 \mathrm{mg}$ for PVA80, $4.3 \mathrm{mg}$ for the PVA 88 range, and $4.8 \mathrm{mg}$ for $99 \%$ hydrolyzed PVA. The fluorophore is only soluble at basic $\mathrm{pH}$, and therefore sodium carbonate is added to adjust the $\mathrm{pH}$. Carrying out the reaction in 0.05 $\mathrm{M} \mathrm{Na}_{2} \mathrm{CO}_{3}$ ( $\mathrm{pH} \mathrm{11)}$ caused PVA to be fully hydrolyzed. Instead, in order to prevent complete hydrolysis, a $0.05 \mathrm{M} \mathrm{Na}_{2} \mathrm{CO}_{3}$ solution was added dropwise until the fluorophore was seen to be dissolved, resulting in a solution of approximately $\mathrm{pH}$ 9. The mixture was stirred in the dark for $48 \mathrm{~h}$ and then dialyzed for several days until pure, changing the water three or four times per day. Visking dialysis tubing (Medicell Membranes Ltd.) with a molecular weight cutoff of $7 \mathrm{kDa}$ was used; this size was to remove unlabeled 5-DTAF as well as impurities such as sodium acetate. By using a benchtop size-exclusion column chromatography method, free 5-DTAF was proved not to be present in purified samples. Portions $(1 \mathrm{~mL})$ of purified and unpurified labeled PVA were added to two separate columns loaded with $20 \mathrm{~g}$ of Sephadex G50 gel. The unpurified fluorescently labeled PVA had a significant gap between large and small eluting molecules, indicative of unlabeled PVA. This was not the case with the pure solution of labeled PVA.

In order to determine the level of labeling of each sample, calibration standards were prepared using a stock solution of PVA (90 $\mathrm{kDa}$ molecular weight) and 5-DTAF, which was serially diluted with $0.2 \% \mathrm{w} / \mathrm{v}$ sodium carbonate. All samples were excited at $392 \mathrm{~nm}$, and the intensity of emission was recorded at $420 \mathrm{~nm}$ using a FP-6200 Jasco fluorescent spectrometer. A calibration curve (Figure S4) was established in order to determine the fluorescent intensity of emitted light associated with 5-DTAF upon excitation. A known amount of 5- 
DTAF was added to a $0.2 \% \mathrm{w} / \mathrm{w}$ solution of PVA in a $0.2 \mathrm{M}$ sodium carbonate solution, and the fluorescent intensity was measured. The data fit a straight line very well $\left(R^{2}>0.95\right)$. The intensities of the samples of purified labeled PVA were compared to the calibration curve, which indicated the equivalent mass of free 5-DTAF. From this was calculated the percentage of alcohol moieties labeled (Table 1).

2.4. Rainfastness Wash-off Tests. Vicia faba (field bean) plants were used in this work (Syngenta UK Ltd.). The plants were grown under controlled conditions and used at approximately growth stage 18 (GS18). "Growth stage" is a term from the BBCH growth scale, a resource that helps to classify the various stages of plant growth (Table S2). ${ }^{39,40}$ Only leaves from leaf position 3 (LP3) were selected to be used. "Leaf position" refers to the position of leaves on the plant, LP1 being the first set of leaves from the bottom of the plant, LP2 being the second set, and so on. The droplets of polymer solution were placed directly onto the leaves at LP3 using a microliter syringe and allowed to dry. The leaves are only removed from the plant at the last moment before imaging.

2.4.1. Laboratory-Scale Wash-off. Droplets $(0.2 \mu \mathrm{L})$ of labeled PVA $(0.4 \% \mathrm{w} / \mathrm{w})$ were placed on the adaxial leaf surface and allowed to dry. The leaf was fixed to a glass slide with sticky tape. The deposit was imaged under a fluorescent microscope (Leica MZ10 F, fitted with an "ET GFP" filter, a camera, and a fiber-optic light source) and then washed with $1 \mathrm{~mL}$ of deionized water so as to imitate rain (Figure 1A). The deposit was then sequentially imaged and washed until it was seen to be removed, or until the number of washes reached 10 , resulting in a series of images that depict the wash-off behavior of each PVA sample. ImageJ software was used to analyze the images by determining the coverage of the fluorescent polymer deposit. The first image was taken as the value for the initial " $100 \%$ coverage", and the subsequent images were quantified as a percentage with regard to the initial dry deposit (Figure 1C). Leaves from plants were used as test surfaces. ImageJ was also used to characterize the diameter of the dry deposits from the captured images.

2.4.2. Raintower Wash-off. Much of this method is as described in section 2.4.1. However, leaves were instead lightly stuck (so as to be removed and replaced) to flexible wooden boards (Figure 1B). These boards were clamped at an angle and placed on rotating platforms under an artificial rain source available at Syngenta (Jealott's Hill International Research Centre). The rain is achieved by pumping water through nozzles near the ceiling and filtering this rain with shutters. Both the flow rate of the pump and the shutter opening can be adjusted in order to tune the droplet size and intensity of the rain. The result is a raintower that is capable of mimicking a number of rain conditions. In nature, low rainfall intensities are characterized by small droplet sizes. ${ }^{41,42}$ In order to achieve this, the flow rate of the water must be high but the shutter opening minimal. Conversely, highintensity natural rain tends to be comprised of large droplets. Therefore, the flow rate is kept low and the shutters are opened much more. Two sets of conditions were selected in order to represent rainfall of medium and high intensities. The intensity of $10 \mathrm{~mm} / \mathrm{h}$ of rain was achieved with an approximate flow rate of $2800 \mathrm{~L} / \mathrm{h}$ water and a shutter opening of $25 \mathrm{~mm}$. A flow rate of $2300 \mathrm{~L} / \mathrm{h}$ and a shutter opening of $55 \mathrm{~mm}$ provided the high-intensity rain of $30 \mathrm{~mm} / \mathrm{h}$. During experimentation, calibrations were made three times per day using graduated rain gauges. The deposits were first imaged dry and then after each wash. Instead of a volume of $1 \mathrm{~mL}$ of water being used as a wash, as in section 2.4.1, the deposits were exposed to $3 \mathrm{~min}$ of rain, termed a "rain event".

\section{RESULTS AND DISCUSSION}

3.1. Characterization of PVA. Results from GPC, ${ }^{1} \mathrm{H}$ NMR, WAXS, and DSC characterization of unlabeled PVA have been collated (Table 1) to provide the $\mathrm{DoH}$ (for both labeled and unlabeled PVA), molecular weights $\left(M_{\mathrm{n}}\right.$ and $\left.M_{\mathrm{w}}\right)$, and crystallinity (unlabeled only) for each PVA sample. ${ }^{1} \mathrm{H}$ NMR shows that the actual DoH is close to the values quoted by the manufacturer, which were approximately 80,88 , and $99 \%$. GPC results for certain samples deviate from manufacturer specifications. In particular, PVA88M and PVA88H were chosen as medium- and high-molecular-weight partially hydrolyzed samples, but GPC shows that the molecular weight values are very similar. WAXS and DSC measurements for crystallinity values were generally in good agreement. That is, the values for high-molecular-weight samples (PVA99M, PVA99H, and PVA99VH) were greater than those for low-molecular-weight samples via both methods, with the exception of PVA88L. This particular sample had an abnormally low polydispersity index (PDI), perhaps explaining the anomalous crystallinity of around 40\% from both DSC and WAXS analysis. Measurement of the static contact angle between droplets of aqueous PVA solutions $(0.2 \% \mathrm{w} / \mathrm{w})$ on Vicia faba leaf surfaces showed that most grades of PVA are able to "wet" the surface of the leaf better than water, except for PVA80. However, there were no statistical differences between the wetting abilities of PVA solutions (Figure S5). Further, measuring the static contact angles of deionized water on cast PVA films was used as a characterization of the susceptibility of PVA films to water penetration (Figure S5).

3.1.1. Swelling and Solubility of PVA Films. Swelling data for solution-cast PVA films are presented in Figure 2. Each graph represents the $\mathrm{SD}$ over time of a particular sample in water at 5,15 , and $25{ }^{\circ} \mathrm{C}$. These temperatures were used in order to approximate different climatic conditions. Positive SDs indicate swelling, while values below zero show a loss of mass and therefore dissolution. Some plots show that samples dissolve within an hour, while some do not dissolve after $24 \mathrm{~h}$.

A trend based on temperature is clearly evident. At lower temperatures, samples universally took longer to reach peak SD and took longer to dissolve than those at higher temperatures. Expectedly, this highlights that temperature does have an important effect on the polymer dissolution; however, only ambient temperature and humidity was used for the laboratoryscale wash-off experiments.

In addition, there is a distinct difference in the results between films of different molecular weights. All films formed with partially hydrolyzed PVA (PVA80, PVA88L, PVA88M, and PVA $88 \mathrm{H})$, with molecular weight $\left(M_{\mathrm{w}}\right)$ ranging between 9 and $33 \mathrm{kDa}$, dissolve within $20 \mathrm{~min}$, while the films of fully hydrolyzed samples (PVA99M, PVA99H, and PVA99VH), with $M_{\mathrm{w}}$ ranging between 51 and $93 \mathrm{kDa}$, do not dissolve even after $24 \mathrm{~h}$. This difference may be attributed to the $\mathrm{DoH}$ as well, but the fully hydrolyzed sample of PVA99L with a molecular weight of approximately $22 \mathrm{kDa}$ also is seen to break apart, if not dissolve, within $20 \mathrm{~min}$.

It was observed that PVA99L dissolved differently from other samples. Instead of a gradual dissolution, it begins to mechanically break apart, making the process of weighing the sample much more difficult, and a larger degree of error can be seen in the results compared with others. After $15 \mathrm{~min}$, although the sample is not dissolved, it is so broken apart that weighing the sample is not feasible. The anomalous behavior is not apparent with any partially hydrolyzed samples of a similar molecular weight or any of the fully hydrolyzed samples of higher molecular weight. Therefore, this unique mechanism of dissolution can be attributed to a combination of the low molecular weight and full $\mathrm{DoH}$ of the sample.

The general trend of the results is that PVA films of high molecular weight and high $\mathrm{DoH}$ resist water dissolution most effectively. There is also evidence that water penetration into the bulk polymer is much more difficult at higher molecular weights. The fact that PVA99VH $(93 \mathrm{kDa})$ has a much lower 


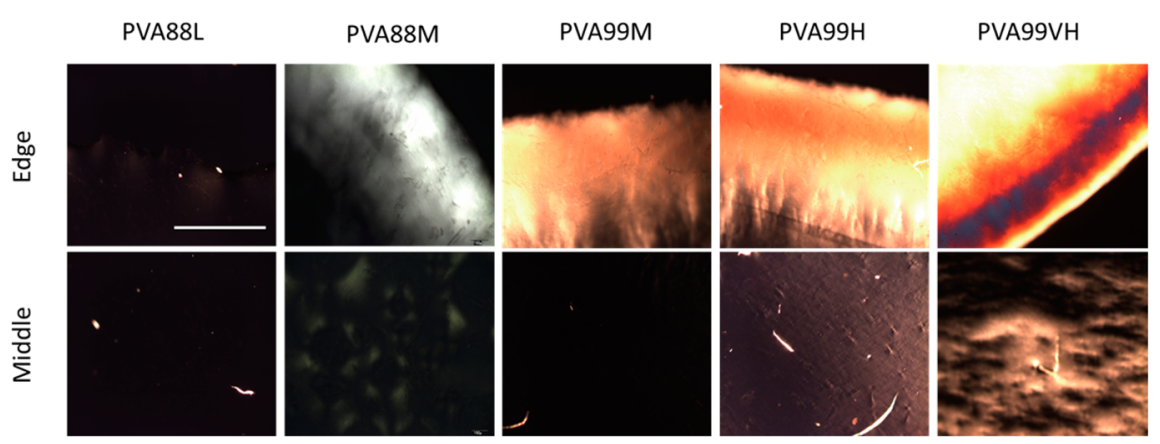

Figure 3. PLM images from 5 PVA films cast on parafilm but detached and viewed on glass slides. Both the edge and middle of the films are shown. Higher contrast indicates a higher degree of anisotropy. The molecular weight increases from left to right, and the scale bar equals $1 \mathrm{~mm}$.

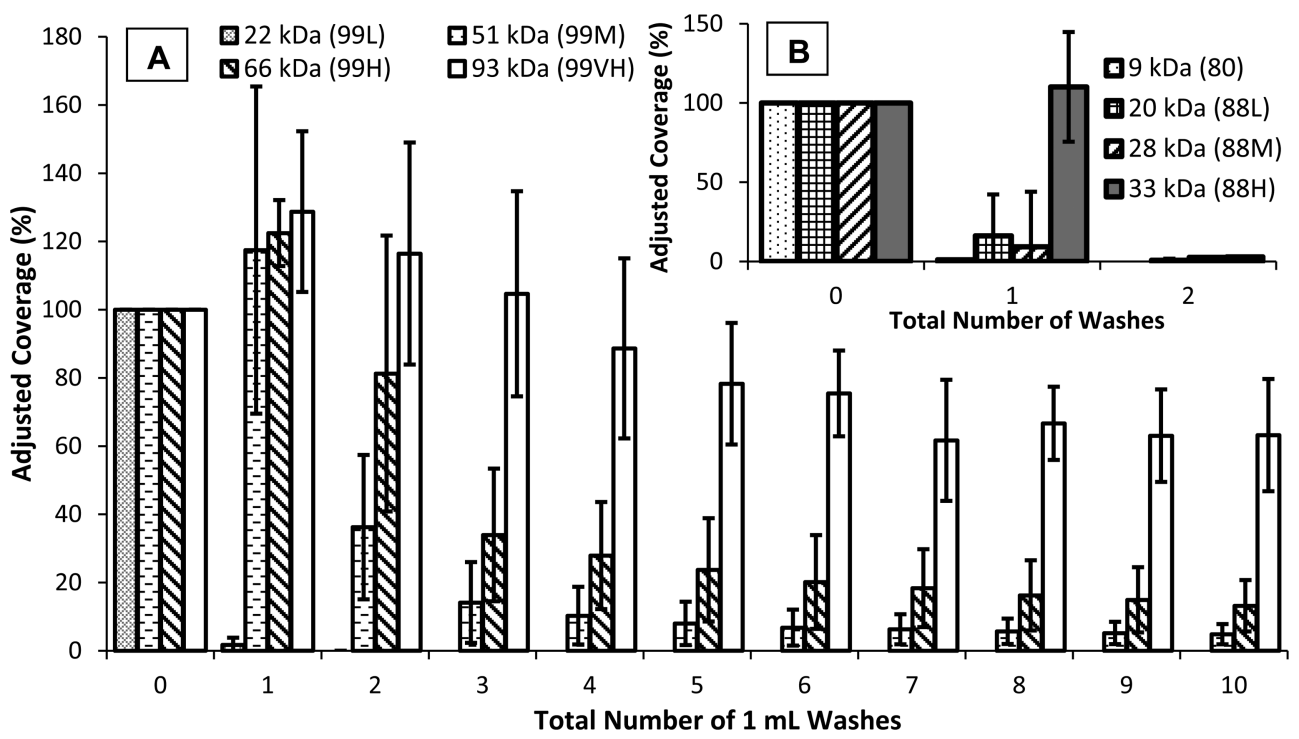

Figure 4. Laboratory-scale wash-off profiles for all eight fluorescently labeled PVA samples, with part A showing the four fully hydrolyzed samples and part B, inset, showing the four partially hydrolyzed samples. Droplets $(0.2 \mu \mathrm{L}, 0.4 \% \mathrm{w} / \mathrm{w})$ were allowed to dry on leaves and imaged prior to sequential washing $(1 \mathrm{~mL})$ and reimaging. Image analysis was used to quantify coverage by adjusting the coverage value of dry deposits to represent $100 \%$ coverage.

maximum swelling number of approximately 2-3 than PVA99M and PVA99H (51 and $66 \mathrm{kDa}$, respectively, and maximum swelling numbers of approximately 6-7) shows that at high molecular weight the penetration of water into the bulk polymer becomes more difficult. Finally, no trend between the static contact angle of deionized water on PVA film surfaces and PVA film swelling and dissolution was found (Figure S5).

3.1.2. PLM. Images obtained from PLM show highercontrast, brighter images when a sample is more anisotropic. Figure 3 indicates that PVA samples of higher molecular weight show greater anisotropic character than those of low molecular weight, particularly at the edge of the sample. The phenomenon observed at the edge of the films is due to the polymer particles being deposited via capillary flow to the edge of the film as the solution evaporates. ${ }^{43}$ This well-known "coffee ring effect" causes aggregation of the polymer material at the edge of the film, inducing order and, thus, anisotropic character. It is evident that, for PVA, greater order is achieved when films are formed from samples of higher molecular weights. It is theorized that the longer polymer chains in these samples are better able to form ordered structures, such as lamellae.

PLM images show good agreement with measured crystallinities of the polymer films, with the exception of
PVA88L. Low-molecular-weight polymers did not produce anisotropic films and showed little crystallinity via DSC or WAXS measurements. The exception of PVA88L, with approximately $40 \%$ crystallinity via DSC and WAXS, did not produce anisotropic films either. Conversely, high-molecularweight PVA with generally higher values of crystallinity did produce anisotropic films.

3.2. Laboratory-Scale Wash-off of Fluorescently Labeled PVA. The field bean wash-off data from images, quantified via ImageJ, are presented in Figure 4. The values for dry deposits are adjusted to represent $100 \%$ coverage. Triplicate values and standard deviation error bars are reported. In many cases, the value of coverage after the first wash increases above $100 \%$. This has been attributed to an initial spreading of the previously aggregated deposit around the leaf surface.

The samples with the lowest molecular weights washed off very readily. For the five lowest-molecular-weight PVA samples, almost $100 \%$ of the coverage is lost by the second or third wash. However, for the three remaining samples (PVA99M, PVA99H, and PVA99VH) with the highest molecular weights, significant coverage is retained after up to 10 washes. After approximately three to five washes a "tenacious" amount of the 
deposit was observed that was only gradually removed during the remaining washes.

There is a threshold molecular weight in the region of 33-52 $\mathrm{kDa}$ over which PVA starts to become more resistant to washoff. Alternatively, this threshold could be described as the molecular weight over which PVA is rainfast. Over this threshold molecular weight, rainfastness correlates linearly with the molecular weight (Figure 5).

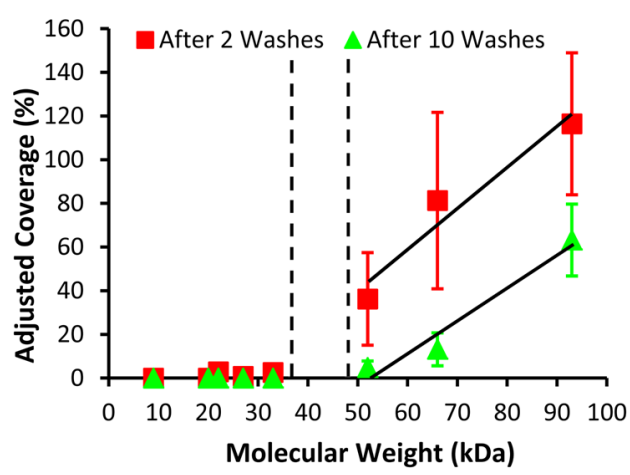

Figure 5. Adjusted coverage of fluorescently labeled PVA deposits of different molecular weights on leaves after 2 and 10 washes, with the dashed lines indicating the threshold region of molecular weight over which samples are rainfast.

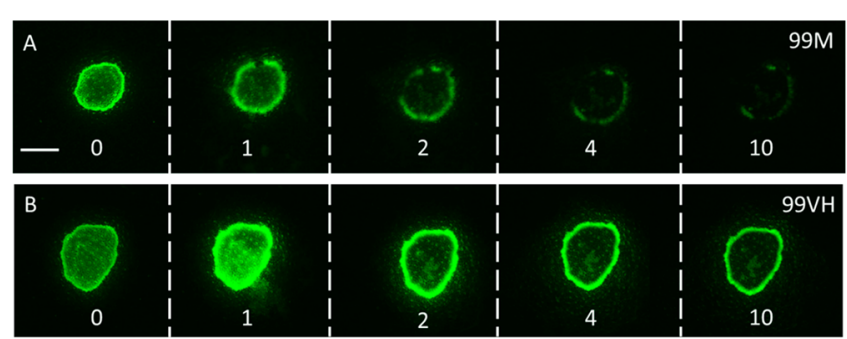

Figure 6. Unprocessed images of PVA99M (A) and PVA99VH (B) deposits on Vicia faba leaf surfaces at various washing stages. The number indicates the amount of washes of $1 \mathrm{~mL}$ of deionized water, where " 0 washes" indicate the initial dry deposit. The scale bar equals $0.8 \mathrm{~mm}$.

Droplets of PVA formulation dry to form deposits with a concentration of material in the annulus (Figure 6). In most cases, the annulus is the last area to be washed away, or it is the area that resists wash-off completely. This is in accordance with observations made using PLM, in which the aggregates at the edge of the deposits were shown to have the greatest order. These areas of the annulus may be acting as films, and so behavior similar to that observed during swelling and solubility is to be expected. Droplets dry to form deposits with irregular shapes. ImageJ was used to calculate the diameters of these deposits in three directions. The diameter of these deposits ranged from a minimum of $0.84 \mathrm{~mm}$ to a maximum of 1.25 $\mathrm{mm}$, with a mean of $1.02 \pm 0.16 \mathrm{~mm}$ and averages for each polymer deposit reported in Table S1. There was no correlation between the diameter of the deposits and the grade of PVA or rainfastness. This indicates that the viscosity of PVA, which is intrinsically linked to the molecular weight, did not affect the size of the deposits. Similarly, there was no correlation between the measured static contact angle of PVA solutions on Vicia faba leaf surfaces and the deposit diameter or rainfastness (Figure S5 and Table S3).
3.3. Raintower Wash-off of Fluorescently Labeled

PVA. As described in section 2.4.2, two rain intensities were generated to wash leaves, 10 and $30 \mathrm{~mm} / \mathrm{h}$. These rain intensities correspond to moderate and heavy rainfall, respectively. ${ }^{44}$ Instead of quantification of the coverage against the number of distinct $1 \mathrm{~mL}$ washes, the experiments have been performed using $3 \mathrm{~min}$ rain events as the washing method. The results from washing deposits with moderate rain (Figure 7) show a trend similar to those results gathered at the laboratory scale (Figure 4). All samples, except the three of highest molecular weight, were washed off by the second or third wash, and the molecular weight dependence was observed in the three samples that showed retention. Using this method, there was more variability in the results, as illustrated with larger standard deviation values, particularly with the sample of PVA99H. The results reach a plateau level of coverage sooner than they do for laboratory-scale results; this suggests that more washing is occurring at the beginning of the raintower study than the laboratory-scale study.

When the rain intensity was increased to $30 \mathrm{~mm} / \mathrm{h}$, several samples that showed no resistance to $10 \mathrm{~mm} / \mathrm{h}$ rain were disregarded. As a consequence, the results comprise five samples (Figure 8). This heavy rain intensity was able to remove all but one sample of PVA after five washes. The bestperforming PVA was again PVA99VH, which was able to resist wash-off for up to 10 washes. Interestingly, the coverage values for this sample of PVA at heavy-intensity rainfall do not vary significantly from the coverage values obtained after lowintensity rain or laboratory-scale washing. This evidence, along with the fact that PVA99M and PVA99H were washed-off readily by the heavy-intensity rain, suggests that an important factor for removing PVA by washing is the intensity of the rainfall rather than the volume or rain exposure time.

3.4. Discussion of Interrelated Properties. The results from swelling of the films and from wash-off of the deposits correlate. Compared to films or labeled deposits of PVA99M, PVA99H, and PVA99VH, films and labeled deposits of PVA80, PVA88L, PVA88M, PVA88H, and PVA99L are much more easily dissolved in water and washed off of leaves. Although partially hydrolyzed samples of PVA contain hydrophobic acetate moieties, the disruption to intra- and intermolecular hydrogen bonding between alcohol moieties reduces the water resistance of these samples. The additional acetate moiety also makes the formation of crystalline regions more difficult, thus decreasing the water resistance.

Typical polymer dissolution models state that, as the solvent begins to penetrate the polymer bulk phase, the polymer surface is transformed from a glassy to a rubbery state, at which point stress may cause the polymer to crack and break apart. $^{45-48}$ These polymer dissolution models for amorphous polymers state that there are continuous layers between pure polymer and pure solvent where dissolution is driven by solvent diffusing toward the pure polymer, with chain disentanglement occurring toward the pure solvent. ${ }^{45}$ The "infiltration layer" consists of the solvent initially entering into normally occurring fissures and holes in the polymer surface. As more water enters, the polymer swells to a greater degree, with the regions of the polymer closest to the solvent eventually becoming a liquid polymer solution. It has previously been reported that polymer films below a threshold molecular weight do not exhibit the gel layer and are likely to crack apart rather than swell and dissolve, as was observed for PVA99L. ${ }^{46}$ It was also reported that films of higher molecular weight swell more. This is not observed in the 


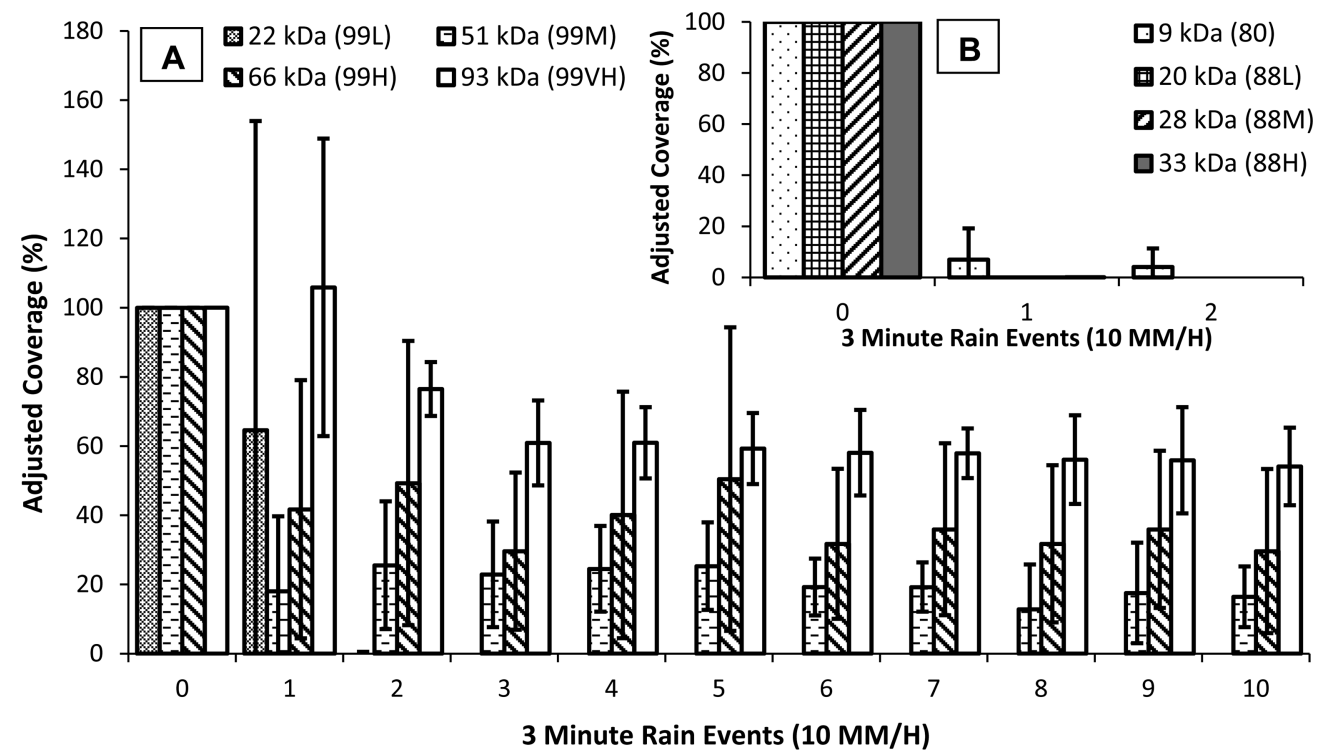

Figure 7. Raintower wash-off profiles for all eight fluorescently labeled PVA samples, with part A showing the four fully hydrolyzed samples and part $\mathrm{B}$, inset, showing the four partially hydrolyzed samples. Droplets $(0.2 \mu \mathrm{L}, 0.4 \% \mathrm{w} / \mathrm{w})$ were allowed to dry on leaves and imaged prior to sequential rain washes and reimaging. Image analysis was used to quantify coverage by adjusting the coverage value of dry deposits to represent $100 \%$ coverage.

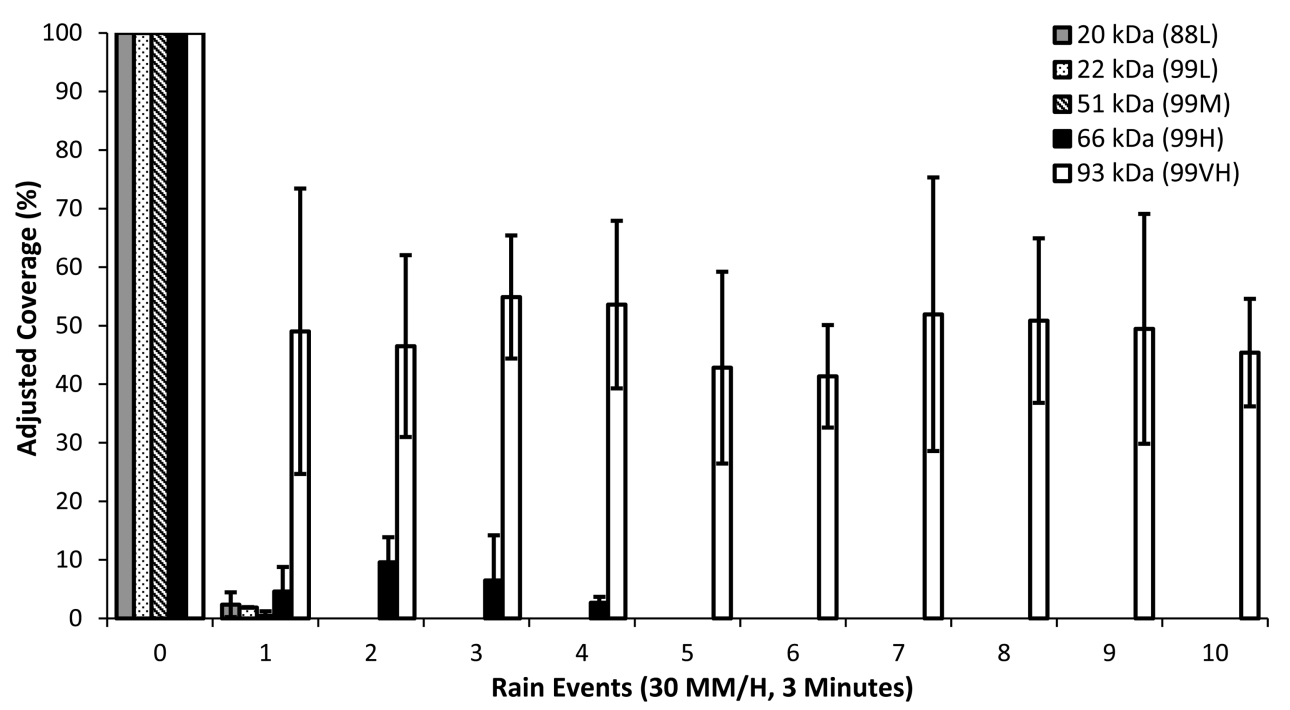

Figure 8. Raintower wash-off profiles for five selected fluorescently labeled PVA samples. Droplets $(0.2 \mu \mathrm{L}, 0.4 \% \mathrm{w} / \mathrm{w})$ were allowed to dry on leaves and imaged prior to sequential rain washes and reimaging. Image analysis was used to quantify coverage by adjusting the coverage value of dry deposits to represent $100 \%$ coverage.

results above, with $93 \mathrm{kDa}$ PVA99VH swelling much less than 51 and $66 \mathrm{kDa}$ PVA99M and PVA99H. This difference is most likely due to the high degree of crystallinity in the highermolecular-weight samples. This is not accounted for in models of amorphous polymer dissolution, where ordered crystalline regions are significantly harder for water to penetrate. The fact that the films of PVA99M, PVA99H, and especially PVA99VH resist water infiltration to such a degree provides an explanation as to the source of its excellent rainfastness performance.

As highlighted by the crystallinity results, PVA is a semicrystalline polymer with a high degree of amorphous character. For crystallinity, a sometimes large discrepancy between the WAXS and DSC results is observed. This has been attributed to the fact that samples are annealed during the heating process, which is inherent for DSC experiments but not for WAXS. With the exception of PVA88L, the samples with the best retention after 10 washes and that resisted dissolution by water as films had the highest degrees of crystallinity. As previously discussed, the three samples that retained well on the leaf surface (PVA99M, PVA99H, and PVA99VH) during laboratory-scale and low-intensity rain washes showed a tenacious amount of coverage, which remained almost constant between the 5th and 10th washes. This behavior could be the result of the dissolution and wash-off of amorphous portions of the polymer, while the crystalline portions remain attached to the leaf. The flexible amorphous domains and rigid, insoluble crystalline domains of such samples may combine to provide the ideal properties to resist physical detachment from the leaf during more rigorous washing.

PVA88L has a much higher degree of crystallinity than other partially hydrolyzed samples, comparable to the highmolecular-weight, fully hydrolyzed samples. It also had an 
unusually high degree of polymerization, leading to the assumption that the degree of crystallinity observed was due to the abundance of similarly sized polymer chains being able to form ordered regions in spite of the unfavorable bulky acetate moiety. This suggests that a high degree of crystallinity alone is not the key factor for rainfastness. Previously it was shown that coverage of PVA deposits does not vary much with continued washings after the second or third wash, at either laboratory scale or raintower scale. By defining rainfastness as the coverage still on the leaf after the second wash, it is possible to compare this quantifiable value with the molecular weight and crystallinity. This highlights that a combination of high molecular weight and a relatively high degree of crystallinity is the key for rainfastness performance (Figure 9).

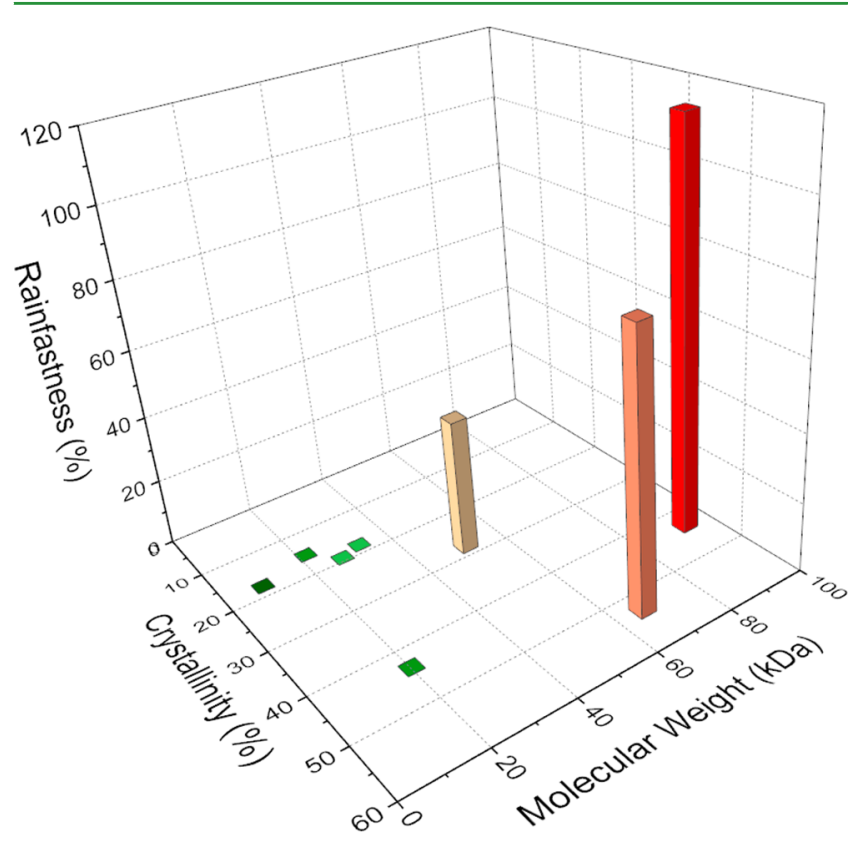

Figure 9. Laboratory-scale rainfastness of fluorescently labeled PVA deposits as a function of the polymer molecular weight and crystallinity.

\section{CONCLUSIONS}

A range of varying grades of PVA have been characterized and fluorescently labeled. Novel methods for quantifying the rainfastness of deposits of these polymers have been established using artificially generated rain and smaller laboratory-scale washing. The methods can be used to test any fluorescently labeled compounds and could be useful tools towards more intelligent design of rainfast formulations. The raintower method has been a worthwhile validation of the laboratoryscale washing method and leads to the conclusion that the laboratory-scale method is a good estimation of rain conditions. The methods established will enable future studies to measure the performance of other polymers. Moreover, incorporating active ingredients into the experimental design will indicate if the polymers are effective at improving the rainfastness of agrochemical formulations. The existence of a critical molecular weight under which PVA is not rainfast and over which the rainfastness scales with the molecular weight has been demonstrated. It has been shown that high-molecular-weight PVA with a high degree of crystallinity is more difficult to wash off of Vicia faba leaves; wash-off results correlate with the behavior of films submerged in water.

\section{ASSOCIATED CONTENT}

\section{Supporting Information}

The Supporting Information is available free of charge on the ACS Publications website at DOI: 10.1021/acsami.6b01682.

Water content in the films and average diameter of dry deposits data, assigned ${ }^{1} \mathrm{H}$ NMR spectrum for PVA, classification of the growth stages for Vivia faba, exemplary DSC thermographs and WAXS patterns, calibration curve for mixtures of 5-DTAF and PVA fluorescence, and static contact angles of PVA solutions on leaf surfaces and deionized water on PVA film surfaces (PDF)

\section{AUTHOR INFORMATION}

\section{Corresponding Author}

*E-mail: v.khutoryanskiy@reading.ac.uk. Tel: +44 (0) 11183786119.

\section{Author Contributions}

All authors have given approval to the final version of the manuscript.

\section{Notes}

The authors declare no competing financial interest.

\section{ACKNOWLEDGMENTS}

We acknowledge the BBSRC (CASE Studentship BB/ J0124401/1) and Syngenta for funding the doctoral project of BLS. We also acknowledge the Chemical Analysis Facility (CAF) at the University of Reading for use of NMR, PLM, WAXS and DSC equipment. Finally, we gratefully acknowledge our colleagues at the University of Reading and Syngenta for their useful input, in particular Stephanie Lucas, Anne Stalker and Jill Foundling.

\section{ABBREVIATIONS}

PVA, poly(vinyl alcohol)

5-DTAF, 5-(4,6-dichlorotriazinyl)aminofluorescein

$\mathrm{DoH}$, degree of hydrolysis

DSC, differential scanning calorimetry

NMR, nuclear magnetic resonance

GPC, gel permeation chromatography

WAXS, wide-angle $\mathrm{X}$-ray scattering

PLM, polarized light microscopy

$M_{n}$, number-average molecular weight

$M_{\mathrm{w}}$, weight-average molecular weight

PDI, polydispersity index

GS, growth stage

LP, leaf position

\section{REFERENCES}

(1) Food and Agriculture Organization of the United Nations. FAO Statistical Yearbook 2013; United Nations: Rome, Italy, 2013.

(2) Knowles, D. A.; Copping, L. G. In Chemistry and Technology of Agrochemical Formulations; Knowles, D. A., Ed.; Springer: Dordrecht, The Netherlands, 1998.

(3) Krogh, K. A.; Halling-Sørensen, B.; Mogensen, B. B.; Vejrup, K. V. Environmental Properties and Effects of Nonionic Surfactant Adjuvants in Pesticides: A Review. Chemosphere 2003, 50 (7), 871901. 
(4) Fujisawa, T.; Ichise, K.; Fukushima, M.; Katagi, T.; Takimoto, Y. Improved Uptake Models of Nonionized Pesticides to Foliage and Seed of Crops. J. Agric. Food Chem. 2002, 50 (3), 532-537.

(5) Wang, C. J.; Liu, Z. Q. Foliar Uptake of Pesticides-Present Status and Future Challenge. Pestic. Biochem. Physiol. 2007, 87 (1), 18.

(6) Green, J. M.; Beestman, G. B. Recently Patented and Commercialized Formulation and Adjuvant Technology. Crop Prot. 2007, 26 (3), 320-327.

(7) Rodham, D. K. Colloid and Interface Science in Formulation Research for Crop Protection Products. Curr. Opin. Colloid Interface Sci. 2000, 5 (5-6), 280-287.

(8) Smith, C. Method and Apparatus for Spraying Agrochemicals. U.S. Patent 3,993,245, 1976.

(9) John, J. Simmons. Seed Coating Machine. U.S. Patent 4,465,017, 1984

(10) Pimentel, D. Amounts of Pesticides Reaching Target Pests: Environmental Impacts and Ethics. J. Agric. Environ. Ethics 1995, 8 (1), $17-29$.

(11) Seaman, D. Trends in the Formulation of Pesticides-An Overview. Pestic. Sci. 1990, 29 (4), 437-449.

(12) Mercer, G. N.; Sweatman, W. L.; Forster, W. A. A Model for Spray Droplet Adhesion, Bounce or Shatter at a Crop Leaf Surface. In Progress in Industrial Mathematics at ECMI 2008; Fitt, A. D., Norbury, J., Ockendon, H., Wilson, E., Eds.; Mathematics in Industry; Springer: Berlin, Germany, 2010; Vol. 15, pp 945-951.

(13) Wirth, W.; Storp, S.; Jacobsen, W. Mechanisms Controlling Leaf Retention of Agricultural Spray Solutions. Pestic. Sci. 1991, 33 (4), 411-420.

(14) Miller, P. C. H.; Ellis, M. C. B. Effects of Formulation on Spray Nozzle Performance for Applications from Ground-Based Boom Sprayers. Crop Prot. 2000, 19, 609-615.

(15) Bertola, V. Effect of Polymer Additives on the Apparent Dynamic Contact Angle of Impacting Drops. Colloids Surf., A 2010, $363(1-3), 135-140$.

(16) Katagi, T. Photodegradation of Pesticides on Plant and Soil Surfaces. Rev. Environ. Contam. Toxicol. 2004, 182, 1-189.

(17) Kudsk, P.; Mathiassen, S. K. Analysis of Adjuvant Effects and Their Interactions with Variable Application Parameters. Crop Prot. 2007, 26 (3), 328-334.

(18) Jha, P.; Norsworthy, J. K.; Scott, R. C. Cyhalofop Application Timing and Adjuvant Selection for Echinochloa Crus-Galli Control in Rice. Crop Prot. 2010, 29 (8), 820-823.

(19) van Zyl, S. a.; Brink, J.-C.; Calitz, F. J.; Coertze, S.; Fourie, P. H. The Use of Adjuvants to Improve Spray Deposition and Botrytis Cinerea Control on Chardonnay Grapevine Leaves. Crop Prot. 2010, 29 (1), 58-67.

(20) Thacker, J. R. M.; Young, R. D. F. The Effects of Six Adjuvants on the Rainfastness of Chlorpyrifos Formulated as an Emulsifiable Concentrate. Pestic. Sci. 1999, 55 (2), 198-200.

(21) Gent, D. H.; Schwartz, H. F.; Nissen, S. J. Effect of Commercial Adjuvants on Vegetable Crop Fungicide Coverage, Absorption, and Efficacy. Plant Dis. 2003, 87 (5), 591-597.

(22) Knezevic, S. Z.; Datta, A.; Scott, J.; Charvat, L. D. Application Timing and Adjuvant Type Affected Saflufenacil Efficacy on Selected Broadleaf Weeds. Crop Prot. 2010, 29 (1), 94-99.

(23) Bunting, J. A.; Sprague, C. L.; Riechers, D. E. Proper Adjuvant Selection for Foramsulfuron Activity. Crop Prot. 2004, 23 (4), 361366.

(24) Ryckaert, B.; Spanoghe, P.; Haesaert, G.; Heremans, B.; Isebaert, S.; Steurbaut, W. Quantitative Determination of the Influence of Adjuvants on Foliar Fungicide Residues. Crop Prot. 2007, 26 (10), $1589-1594$.

(25) Hunsche, M.; Damerow, L.; Schmitz-Eiberger, M.; Noga, G. Mancozeb Wash-off from Apple Seedlings by Simulated Rainfall as Affected by Drying Time of Fungicide Deposit and Rain Characteristics. Crop Prot. 2007, 26 (5), 768-774.

(26) Cai, D.; Wang, L.; Zhang, G.; Zhang, X.; Wu, Z. Controlling Pesticide Loss by Natural Porous Micro/nano Composites: Straw Ash-
Based Biochar and Biosilica. ACS Appl. Mater. Interfaces 2013, 5 (18), 9212-9216.

(27) Kettel, M. J.; Schaefer, K.; Groll, J.; Moeller, M. Nanogels with High Active $\beta$-Cyclodextrin Content as Physical Coating System with Sustained Release Properties. ACS Appl. Mater. Interfaces 2014, 6 (4), 2300-2311.

(28) Nadiminti, P. P.; Dong, Y. D.; Sayer, C.; Hay, P.; Rookes, J. E.; Boyd, B. J.; Cahill, D. M. Nanostructured Liquid Crystalline Particles as an Alternative Delivery Vehicle for Plant Agrochemicals. ACS Appl. Mater. Interfaces 2013, 5 (5), 1818-1826.

(29) Jia, X.; Sheng, W.-B.; Li, W.; Tong, Y.-B.; Liu, Z.-Y.; Zhou, F. Adhesive Polydopamine Coated Avermectin Microcapsules for Prolonging Foliar Pesticide Retention. ACS Appl. Mater. Interfaces 2014, 6 (22), 19552-19558.

(30) Zhang, W.; He, S.; Liu, Y.; Geng, Q.; Ding, G.; Guo, M.; Deng, Y.; Zhu, J.; Li, J.; Cao, Y. Preparation and Characterization of Novel Functionalized Prochloraz Microcapsules Using Silica-Alginate-Elements as Controlled Release Carrier Materials. ACS Appl. Mater. Interfaces 2014, 6 (14), 11783-11790.

(31) Percival, G. C.; Keary, I. P.; Marshall, K. The Use of FilmForming Polymers to Control Guignardia Leaf Blotch and Powdery Mildew on Aesculus Hippocastanum L. and Quercus Robur L. Arboric. Urban For. 2006, 32 (3), 100-107.

(32) Percival, G. C.; Fraser, G. A. The Influence of Commercial FilmForming Polymers on Reducing Salt Spray Injury in Evergreen Oak (Quercus Ilex L.) and Laurel (Prunus Laurocerasus L.). Arboric. Urban For. 2007, 33 (May), 185-192.

(33) Webb, D. A.; Holloway, P. J.; Western, N. M. Effects of Some Surfactants on Foliar Impaction and Retention of Monosize Water Droplets. Pestic. Sci. 1999, 55 (3), 382-385.

(34) Smith, D. B.; Askew, S. D.; Morris, W. H.; Shaw, D. R.; Boyette, M. Droplet Size and Leaf Morphology Effects on Pesticide Spray Deposition. Trans. ASAE 2000, 43 (2), 255-259.

(35) Ennis, W. B.; Williamson, R. E.; Dorschner, K. P. Studies on Spray Retention by Leaves of Different Plants. Weeds 1952, 1 (3), 274-286.

(36) Paradelo, M.; Arias-Estévez, M.; Nóvoa-Muñoz, J. C.; PérezRodríguez, P.; Torrado-Agrasar, A.; López-Periago, J. E. Simulating Washoff of Cu-Based Fungicide Sprays by Using a Rotating Shear Device. J. Agric. Food Chem. 2008, 56 (14), 5795-5800.

(37) Pérez-Rodríguez, P.; Soto-Gómez, D.; López-Periago, J. E.; Paradelo, M. Modeling Raindrop Strike Performance on Copper Wash-off from Vine Leaves. J. Environ. Manage. 2015, 150, 472-478.

(38) Peresin, M. S.; Habibi, Y.; Zoppe, J. O.; Pawlak, J. J.; Rojas, O. J. Nanofiber Composites of Polyvinyl Alcohol and Cellulose Nanocrystals: Manufacture and Characterization. Biomacromolecules 2010, 11 (3), 674-681.

(39) Lancashire, P. D.; Bleiholder, H.; Van Den Boom, T.; Langelüddeke, P.; Stauss, R.; Weber, E.; Witzenberger, A. A Uniform Decimal Code for Growth Stages of Crops and Weeds. Ann. Appl. Biol. 1991, 119 (3), 561-601.

(40) Meier, U. Growth Stages of Mono- and Dicotyledonous Plants. BBCH Monograph; German Federal Biological Research Centre for Agriculture and Forestry: Berlin, Germany, 2001.

(41) Beard, K. V. Terminal Velocity and Shape of Cloud and Precipitation Drops Aloft. J. Atmos. Sci. 1976, 33 (5), 851-864.

(42) Qadri, F. The Reactive Triazine Dyes: Their Usefulness and Limitations in Protein Purifications. Trends Biotechnol. 1985, 3 (1), 7 12.

(43) Deegan, R. D.; Bakajin, O.; Dupont, T. F.; Huber, G.; Nagel, S. R; Witten, T. A. Capillary Flow as the Cause of Ring Stains from Dried Liquid Drops. Nature 1997, 389, 827-829.

(44) Llasat, M.-C. An Objective Classification of Rainfall Events on the Basis of Their Convective Features: Application to Rainfall Intensity in the Northeast of Spain. Int. J. Climatol. 2001, 21 (11), $1385-1400$

(45) Miller-Chou, B. A.; Koenig, J. L. A Review of Polymer Dissolution. Prog. Polym. Sci. 2003, 28 (8), 1223-1270. 
(46) Polyvinyl Alcohol: Properties and Applications; Finch, C. A., Ed.; Wiley: New York, 1973.

(47) Okamura, S.; Kodama, T.; Higashimura, T. The Cationic Polymerization of T-Butyl Vinyl Ether at Low Temperature and the Conversion into Polyvinyl Alcohol of Poly-T-Butyl Vinyl Ether. Makromol. Chem. 1962, 53 (1), 180-191.

(48) Tubbs, R. K. Melting Point and Heat of Fusion of Poly(vinyl Alcohol). J. Polym. Sci., Part A: Gen. Pap. 1965, 3 (12), 4181-4189. 